\title{
Early autonomic and cognitive dysfunction in PD, DLB and MSA: blurring the boundaries between $a$-synucleinopathies
}

\author{
Giovanni Palermo ${ }^{1} \cdot$ Eleonora Del Prete ${ }^{1} \cdot$ Ubaldo Bonuccelli $^{1} \cdot$ Roberto Ceravolo $^{1}$
}

Received: 11 May 2020 / Revised: 5 June 2020 / Accepted: 8 June 2020 / Published online: 27 June 2020

(c) Springer-Verlag GmbH Germany, part of Springer Nature 2020

\begin{abstract}
Differential diagnosis between Parkinson's disease, dementia with Lewy bodies and multiple system atrophy can be difficult, especially because in early phase they might present with overlapping clinical features. Notably, orthostatic hypotension and cognitive dysfunction are common nonmotor aspects of parkinsonian syndromes and can be both present from the earliest stages of all $\alpha$-synucleinopathies, indicating a common neurobiological basis in their strong relationship. In view of the increasing awareness about the prevalence of mild cognitive dysfunction in multiple system atrophy, the relevance of autonomic dysfunction in demented parkinsonian patients, the critical role of non-motor symptoms in clustering Parkinson's disease patients and the shift to studying patients in the prodromal phase, we will discuss some intrinsic limitations of current clinical diagnostic criteria, even when applied by movement disorder specialists. In particular, we will focus on the early coexistence of autonomic and cognitive dysfunction in the setting of overt or latent parkinsonism as pitfalls in the differential diagnosis of $\alpha$-synucleinopathies. As early and accurate diagnosis remains of outmost importance for counselling of patients and timely enrolment into disease-modifying clinical trials, a continuous effort of research community is ongoing to further improve the clinical diagnostic accuracy of $\alpha$-synucleinopathies.
\end{abstract}

Keywords Orthostatic hypotension · Cognitive impairment $\cdot$ Synucleinopathies $\cdot$ Parkinson's disease $\cdot$ Multiple system atrophy $\cdot$ Dementia with Lewy bodies

\section{Introduction}

$\alpha$-Synucleinopathies are neurodegenerative diseases characterized by the abnormal accumulation of $\alpha$-synuclein $(\alpha$ Syn) aggregates in neurons and glial cells. They include Parkinson's disease (PD), dementia with Lewy bodies (DLB), and multiple system atrophy (MSA). The classification of these disorders is based on the clinical presentation, cellular location, and spatio-temporal development of aberrant $\alpha$-Syn pathology, but they are clinically and pathologically overlapping disorders. In PD and DLB, $\alpha$-Syn aggregates are in the neuronal cytoplasm and axonal processes into Lewy bodies and Lewy neurites, respectively, whereas $\alpha$-Syn inclusions in oligodendroglia are the recognized neuropathologic hallmarks of MSA [1]. Differentiation between PD, DLB and

Roberto Ceravolo

roberto.ceravolo@unipi.it

1 Neurology Unit, Department of Clinical and Experimental Medicine, University of Pisa, Building 13, Santa Chiara Hospital, Via Roma 67, 56122 Pisa, Tuscany, Italy
MSA continues to be a problematic diagnostic dilemma [2]. At this end, here, we will describe three patients with a similar profile of initial symptomatology but who received a different clinical diagnosis by specialists in movement disorders according to the current diagnostic criteria. We will highlight a major degree of overlap between these conditions, especially focusing on the insidious and early coexistence of autonomic and cognitive dysfunction in the setting of overt or latent parkinsonism as pitfalls in the differential diagnosis of parkinsonian syndromes.

\section{Case 1 presentation}

A 65-year-old left-handed male presented to a first neurological visit after a transient loss of consciousness. He had previously been seen by cardiologist who had excluded cardiovascular disorders. The patient's past medical history included only a recent diagnosis of benign prostatic hypertrophy and he was taking no medications. The patient's syncope occurred upon standing and a history of recurring, short-lasting symptoms upon postural challenge, 
including light-headedness or visual disturbances, that began 2 years ago, was noted. Moreover, the neurological exam provided additional clues, revealing parkinsonian features, so that the patient was referred to our movement disorder clinic. At time of consultation, he described balance impairments associated with slow gait and reduced dexterity in fine motor skills with the right hand for the last year. At examination, there was clear evidence of mild bilateral parkinsonism with a prevalence of rigidity and bradykinesia in the right arm and right leg. Cerebellar and pyramidal tract signs were absent. Mild postural instability was noted. He was well oriented and reported no difficulties performing his work, but he complained a 2-year history of subjective memory disturbances involving mainly perceived difficulties with concentration and episodic memory, that do not disrupt daily activities. A detailed neuropsychological evaluation showed executive dysfunction, mild deficits in verbal memory and difficulties in the clock-drawing test consistent with a multidomain cognitive impairment. Additionally, he reported several nonmotor features suggestive of $\alpha$-synucleinopathies, rapid eye movement (REM) sleep behavior disorder (RBD), constipation, and urinary urgency. Brain magnetic resonance imaging (MRI) was normal. Orthostatic change in blood pressure (BP) was measured finding an orthostatic fall in systolic BP of $20 \mathrm{mmHg}$ and in diastolic $\mathrm{BP}$ of $10 \mathrm{mmHg}$. Autonomic function testing confirmed the hypotensive response on tilt-table testing and a lack of vasoconstriction during Valsalva maneuver. Dopamine transporter imaging single photon emission computed tomography (DAT-SPECT) was consistent with neurodegenerative parkinsonism. As a result of mild parkinsonism and prevailing autonomic symptoms, levodopa therapy was initially postponed.

A diagnosis of possible MSA-parkinsonian subtype (MSA-P) was made.

Yet, the severity and distribution of nonmotor symptoms was relatively stable over the next 2 years. Of note, global cognition scores declined slightly over the first 6 years. Initiation of levodopa was associated with improvement in motor symptoms and motor complications (both fluctuations and dyskinesias) emerged after 4 years of levodopa therapy. ${ }^{[} 1222^{]}$I-metaiodobenzylguanidine ( ${ }^{[123]}$ I-MIBG) scintigraphy, performed 2 years after the onset of the symptoms, showed reduced cardiac sympathetic innervation. The patient's condition deteriorated after 7 years because of increasing confusion, disturbed sleep, and visual hallucinations, reflecting the progression of cognitive dysfunction to frank dementia. Freezing of gait and postural instability became a substantial cause of motor disability after 8 years from the diagnosis. Death ensued after 2 years at a nursing home.

Could we refine the diagnosis from MSA-P to PD?

\section{Case 2 presentation}

A 67-year-old right-handed male was seen at the memory clinic because he reported a 2-year history of subjective cognitive impairment, without effects on daily functioning. His history was significant for hypertension and dyslipidemia. Brain MRI was normal. Mini-Mental State Examination (MMSE) was reported as normal, but cognitive testing showed prominent deficits on executive function tests, verbal fluency, and visual recognition memory test. He received an initial diagnosis of non-amnestic mild cognitive impairment (MCI). However, constipation, orthostatic dizziness, urge incontinence, and RBD were reported. Taken together, these findings could suggest the existence of Lewy body pathology and the case was discussed with a movement disorder specialist. At examination, he presented a general impression of movement poverty and subtle motor signs, such as reduced left arm swing, mild stiffness, and slowed finger tapping in the left hand, were detected. Orthostatic intolerance was more prominent in the morning and it was likely resulted in sporadic syncopal episodes. Patient was evaluated for the presence of orthostatic hypotension $(\mathrm{OH})$ and drop in systolic $\mathrm{BP}>30 \mathrm{mmHg}$ within 3 min after adopting the standing position was observed. Head-up tilting and the blood pressure response to the Valsalva manoeuvre confirmed the autonomic failure as well as presynaptic dopaminergic imaging with SPECT-detected nigrostriatal degeneration. However, his most bothersome symptoms were memory disturbances and distractibility. An 18F-fluorodeoxyglucose positron emission tomography ( ${ }^{18 \mathrm{~F}} \mathrm{FDG}-\mathrm{PET}$ ) was characterized by a relative hypometabolism of the frontal and parieto-temporal cortices. When he started levodopa, a transient beneficial response was also reported.

Overall, the presence of all these features in MCI patients alerted us that this could be the early stage of DLB.

However, a second brain MRI was repeated after 2 years providing evidence of characteristic putaminal atrophy as well as the putaminal rim sign. Thereafter, he experienced a fast progression with the development of urinary incontinence and incomplete bladder emptying, postural instability, dementia and dysphagia within the next 5 years. The patient died 2 years later at the age of 74 years as a result of acute aspiration pneumonia.

Should we refine the initial diagnosis from prodromal $D L B$ to MSA-P?

\section{Case 3 presentation}

A 74-year-old right-handed woman with a 7-month history of postural dizziness, sleep disturbances, and memory problems presented to the neurology clinic. Her family noted also changes in gait and slowness of movements. In the suspect of parkinsonism, the patient was referred to our movement disorder clinic. At time of consultation, she showed 
decreased mimicry and an asymmetrical (right $>$ left) akinetic-rigid syndrome with a shuffling gait. The Unified Parkinson's Disease Rating Scale (UPDRS) part III was 15. Her specific comorbidities included glaucoma and osteoporosis. She reported orthostatic intolerance, urinary incontinence, and constipation. RBD was documented on polysomnogram. MMSE was normal but cognition was assessed with a standardized test battery, showing mild deficits in executive function and letter fluency, without any impact on the patient's autonomy. There was significant autonomic dysfunction as demonstrated by BP readings in clinic and subsequent autonomic testing (with a sustained fall in systolic BP of $>20 \mathrm{mmHg}$ ). Brain MRI was unremarkable. DAT-SPECT was consistent with bilateral reduced presynaptic nigrostriatal function. ${ }^{18 \mathrm{~F}}$ FDG-PET did not identify hypometabolic areas. Improvement in motor symptoms was reported with low-dose levodopa therapy.

A diagnosis of probable PD was made.

However, during follow-up, cognitive disturbances progressed to dementia after 2 years, she increasingly showed hypo- and bradykinetic signs and she developed further nonmotor features (well-formed visual hallucinations and cognitive fluctuations), which increased the uncertainty of the PD diagnosis, resulting in the diagnostic dilemma between $\mathrm{PD}$ and DLB.

Should we refine the initial diagnosis from PD to prodromal DLB?

The Ethics Committee of our institution approved this article and all patients gave written informed consent.

\section{Discussion}

This study confirms that early differential diagnosis between $\alpha$-synucleinopathies can be difficult, especially because they might initially present with overlapping clinical features [3]. All $\alpha$-synucleinopathies have in common autonomic nervous system dysfunctions, comprising $\mathrm{OH}$, thermoregulatory, urogenital dysfunction, and gastrointestinal symptoms [4]. Of note, symptoms of $\mathrm{OH}$ have been reported in $18-58 \%$ of PD patients, $30-50 \%$ of DLB patients, and $81 \%$ of MSA patients [5-7]. Also, cognitive impairment in PD is a highly common complication of late-stage disease [8], heralds the onset of illness in advance of parkinsonian motor signs in DLB [9] and is common in both MSA subtypes (the MSA-P and the cerebellar variant, MSA-C) [10]. Importantly, autonomic dysfunction and cognitive impairment can be both present from the earliest phase of all $\alpha$-synucleinopathies, independent of medication [11-14]. Additionally, there is now great interest in the idea that the nonmotor features of $\alpha$-synucleinopathies may even precede diagnosis by several years, constituting 'prodromal' PD, DLB, and MSA [15-17].

This study reinforces the concept of clinical overlap between PD, DLB, and MSA-P, highlighting possible critical issues associated with current clinical criteria due to the increased recognition of dysautonomia and cognitive dysfunction as common nonmotor symptoms across different $\alpha$-synucleinopathies (Fig. 1). Nonetheless, a critical distinction in clinical practice and research is important because the treatment and prognosis of patients with PD and those with atypical parkinsonian disorders differ. Moreover, this is also relevant to inform clinical studies on which subjects may be most suitable for inclusion in neuroprotective trials. We acknowledge that the diagnostic accuracy of clinical assessment should be evaluated using pathologic examination as
Fig. 1 Graphical representation of possible overlaps of orthostatic hypotension and cognitive disturbances in dementia with Lewy bodies, Parkinson's disease and multiple system atrophy. Differential diagnosis, especially in early stages, can be difficult when orthostatic hypotension and cognitive impairment are both present but with mild severity

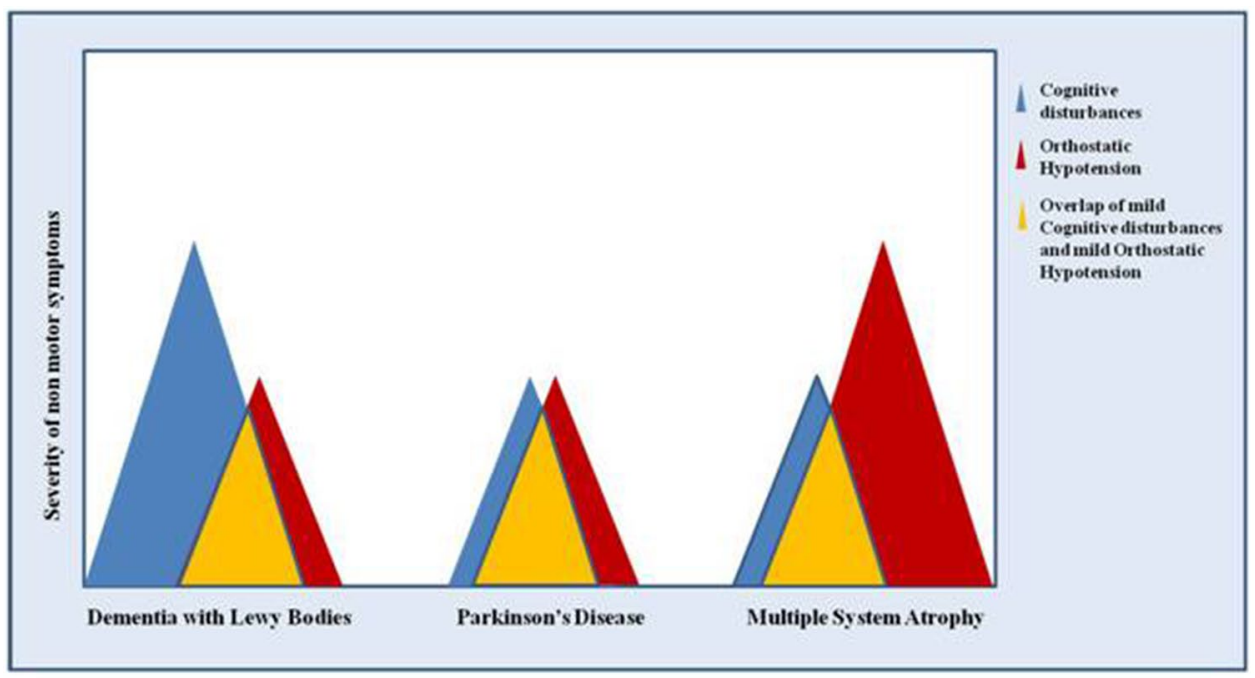


gold standard so that the lack of neuropathological confirmation represents the main limitation of this work. However, diagnosis was clinically confirmed in our patients using strict published criteria and long-term clinical follow-up throughout their illness until death and was further supported by neuroimaging tools. Indeed, patients were reassessed by movement disorders neurologists every 6 months and treated in line with best clinical judgement.

\section{Current diagnostic criteria for a-synucleinopathies: where are we about dysautonomia and cognitive impairment?}

Currently, the diagnosis of PD relies on the recognition of the cardinal motor features and can be guided by the Movement Disorder Society (MDS) new clinical diagnostic criteria combining supportive and exclusionary clinical findings and clinical 'red flags' to assist the diagnosis (Fig. 2) [18]. 'Red flags' include "Severe autonomic failure in the first 5 years of disease as $\mathrm{OH}$ defined as orthostatic decrease of blood pressure within 3 min of standing by at least $30 \mathrm{~mm} \mathrm{Hg}$ systolic or $15 \mathrm{~mm} \mathrm{Hg}$ diastolic, in the absence of dehydration, medication, or other diseases that could plausibly explain autonomic dysfunction or severe urinary retention or urinary incontinence in the first 5 years of disease (excluding long-standing or small amount stress incontinence in women), that is not simply functional incontinence, and in men urinary retention not attributable to prostate disease, but associated with erectile dysfunction". On the other hand, in contrast with previous diagnostic criteria [19-21], the MDS-PD criteria do not consider dementia as an exclusion criterion for PD or as a 'red flag' suggestive of alternative diagnosis [18].

Diagnosis of MSA is based on consensus criteria that rely on either the presence of severe $\mathrm{OH}$ or urinary dysfunction indicating pathological involvement of autonomic neurons [22], whereas cognitive impairment is not a typical presenting feature of patients with MSA. Of note, these guidelines emphasize the importance of autonomic failure, defined as "urinary incontinence (inability to control the release of urine from the bladder, with erectile dysfunction in males) or an orthostatic decrease of blood pressure within 3 min of standing by at least $30 \mathrm{~mm} \mathrm{Hg}$ systolic or $15 \mathrm{~mm} \mathrm{Hg}$ diastolic", for the diagnosis of probable or possible MSA (Fig. 2) [22].

DLB diagnostic criteria require the presence of specific core features such as fluctuating cognition, visual hallucinations, spontaneous parkinsonism, and RBD. OH and urinary incontinence are currently included as supportive features for clinical diagnosis (Fig. 2) [9]. However, in contrast to PD and MSA, OH is not otherwise specified. Additionally, other supportive clinical features for diagnosis of DLB such as repeated falls, syncope, and other transient episodes of unresponsiveness can also be partly attributable to the presence of autonomic dysfunction [23].

Initial PD diagnosis is overall reconsidered in $10-30 \%$ of the patients during the follow-up and some "atypical" cases can be missed. Data from three different research groups report a diagnostic accuracy of only 58\% for parkinsonian subjects with an initial, early diagnosis of PD [24-26] and the most common neuropathological findings in those with clinically diagnosed PD who did not have PD at autopsy have been either MSA or progressive supranuclear palsy (PSP) [27]. The implementation of MDS-PD criteria have recently been reported to improve predictive value, such that over $95 \%$ of cases are accurately diagnosed [28]. However, diagnostic inaccuracy has also been reported using clinical biomarkers for PD [29]. Indeed, PD is highly heterogeneous in terms of clinical presentation as well as rate of progression and risk of disease complications and many patients may not follow the classic progression with variable clinicopathologic phenotypes and natural history [30]. Many different groupings or subtype classification systems have been proposed, according to predefined criteria [e.g., young vs old age at onset or dominance of tremor vs bradykinesia/rigidity] or through a data-driven approach like cluster analysis, in which the profile of the subtypes arise from the data with no a priori hypothesis [31]. PD subtypes based on motor features are most commonly used, but specific clinical descriptions of nonmotor symptom-dominant phenotypes have been recently defined [32] and most critical determinants of PD subtype and prognosis have been identified in the presence of MCI, RBD, and $\mathrm{OH}$ at baseline [33]. The same authors performed a cluster analysis using a different set of variables from Parkinson's Progression Markers Initiative (PPMI) data and found that these nonmotor features were the three key clustering variables to identify a 'diffuse malignant' clinical subtype in a minority of people with PD (10-25\%) in which a broad range of key nonmotor symptoms is associated with prominent motor disability at early stages and faster progression, suggesting a severe and simultaneous involvement of dopaminergic and non-dopaminergic pathways at baseline [34]. A recent review reinforced the association of $\mathrm{OH}$ and $\mathrm{RBD}$ with a malignant phenotype of PD characterized by early cognitive deficits, postural instability and reduced survival rate [35]. Furthermore, there is clear evidence that PD patients have autonomic symptoms and subtle changes in cognition years before the diagnosis of disease [15]. However, early and profound autonomic dysfunction is considered a 'red flag' against PD in MDS diagnostic criteria as well as there is much debate regarding the nosological classification of combined dementia and parkinsonism at disease onset [18].

Autonomic failure represents the most frequent reason for misdiagnosing PD or DLB as MSA. A recent clinicopathological study has revealed that, of 134 patients clinically 


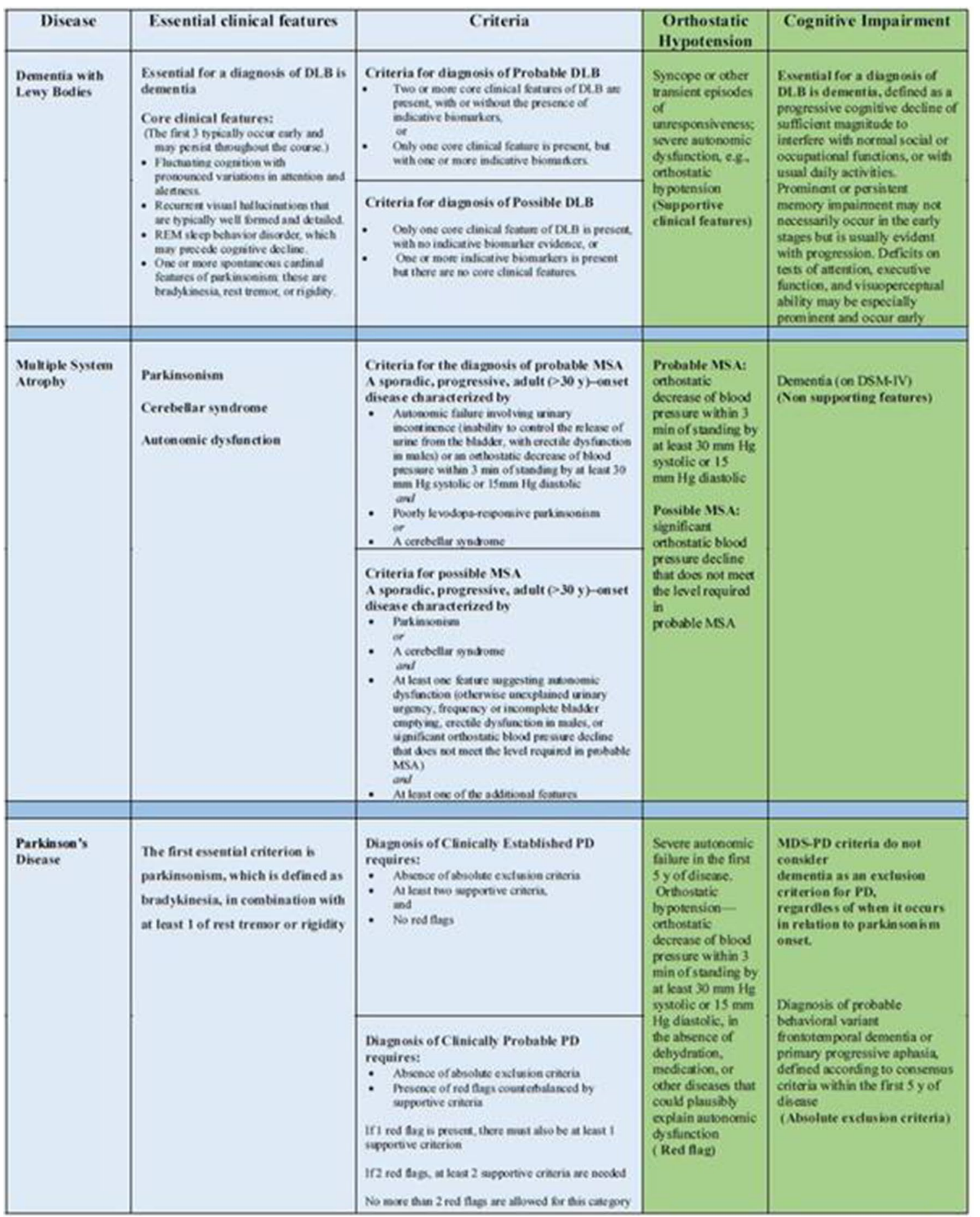

Fig. 2 The different weight of orthostatic hypotension and cognitive impairment in DLB, MSA, and PD according to current diagnostic criteria ( adapted from McKeith et al. [9], Gilman et al. [22], Postuma et al. [18]). DLB dementia with Lewy bodies, DSM-IV Diagnostic and

diagnosed with MSA meeting the diagnostic criteria for probable or possible MSA, only 83 (62\%) had pathologically confirmed MSA and DLB was the pathologic diagnosis in 19 patients (37\%) [36]. An even larger study of
Statistic Manual of Mental Disorder, $P D$ Parkinson's disease, MDS Movement Disorders Society, MSA multiple system atrophy, REM rapid eye movement

203 patients with an ante-mortem diagnosis of MSA showed that only $79 \%$ had pathologically confirmed MSA and misdiagnosed patients mainly had Lewy body disease or PSP pathology [37]. As a result, a detailed critique of the second 
consensus criteria for MSA was recently published [10], and a third revision was initiated in 2018 under the auspices of the International Parkinson and Movement Disorder Society (Fig. 2).

Similarly, the diagnosis of DLB may be challenging especially early in the course, as the clinical presentation is extremely variable among individual patients. A recent meta-analysis of the diagnostic accuracy of the clinical criteria found that about $20 \%$ of DLB diagnoses were incorrect and PD justified a relevant percentage of misdiagnosis (up to 10.8\%) [38]. New revised DLB consensus criteria have been recently updated for a more accurate and early diagnosis [9].

\section{Dysautonomia across a-synucleinopathies}

Among parkinsonian patients in whom $\mathrm{OH}$ is an early or dominant finding, the alternative diagnosis of MSA is usually favored [39]. However, dysautonomia is not specific to MSA and does not develop simultaneously with motor symptoms in many MSA patients, contributing to delay a correct diagnosis [40]. Furthermore, MSA does not start with autonomic failure in all patients and, depending on the study setting, rates of autonomic failure of up to $50 \%$ are reported at MSA disease onset [41]. While it is true that autonomic involvement tends to be more severe and widespread and to have a more rapid progression in MSA compared with patients who have PD [42], there are no clear-cut clinical criteria allowing physicians to discard MSA from idiopathic PD and the assessment of $\mathrm{OH}$ by formal laboratory testing has been found insufficient for differentiating among MSA and PD [43]. Moreover, autonomic symptoms are not always easily quantified and only some of these tests can be performed easily in routine clinical practice [44]. The site of the lesion might distinguish MSA from PD and, classically, it is believed that autonomic dysfunction is a result of preganglionic dysfunction in MSA and postganglionic part of the autonomic nervous system in PD [45]. Of note, in contrast to PD, MSA patients show a greater involvement of the central autonomic network, primarily related to degeneration of preganglionic neurons of the brainstem and spinal cord, a more severe impairment of baroreflex activity and a relative preservation of plasma norepinephrine concentrations, consistent with the presence of intact noradrenergic nerve terminals [46]. Accordingly, scintigraphy with ${ }^{[} 122$ I-MIBG has been proposed for quantification of postganglionic sympathetic cardiac innervation and differential diagnosis of PD from MSA. However, recent evidence has challenged this view because ${ }^{[} 122^{]}$I-MIBG uptake results to be decreased in up to one-third of MSA patients, independent of disease duration and severity [47]. Furthermore, recent studies have emphasized that its diagnostic performance is limited in the early stages of PD [48] and patients with PD with autonomic failure can be indistinguishable from those with MSA in $\mathrm{OH}$ [49]. It has been shown that up to $60 \%$ of PD patients with $\mathrm{OH}$ had already suffered from the symptom in the early phase of $\mathrm{PD}$, even though most of these patients can be asymptomatic [50, 51] and even in some postmortem studies, early $\mathrm{OH}$ was recorded in autopsy-proven PD patients misdiagnosed as MSA [52, 53]. Conversely, one-third of patients with pathologically proven MSA die misdiagnosed with PD [54]. It is worth to mention that brain MRI could aid in the differential diagnosis of parkinsonian syndromes and should be included in the initial evaluation of every patient with suspected atypical parkinsonism since specific MR abnormalities were reported to have high specificity for the diagnosis of MSA [55]. Unfortunately, the sensitivity of MR atrophy patterns is low, especially in early disease stages, and it is correlated with the magnetic field strength. Furthermore, relatively few studies have evaluated the role of MRI in the early diagnosis of MSA [56]. Similarly, a severe bilateral hypometabolism in the striatum, frontal cortex, cerebellum, and brainstem can be considered a specific pattern of glucose metabolism in MSA [57]. However, ${ }^{18 \mathrm{~F}}$ FDG-PET is not available everywhere and its sensitivity is variable. In contrast, substantia nigra hyperechogenicity in transcranial sonography (TCS) has proven useful for PD diagnosis offering good diagnostic reliability at a low cost beyond the research setting. However, conflicting data exist regarding the capacity of TCS to distinguish atypical parkinsonisms from PD, a missing temporal bone window is present in 10-20\% of subjects, and it is heavily dependent on the investigator's experience and technical skills [58]. Additionally, supine resting plasma norepinephrine levels seem able to predict whether the DLB/ PD or MSA will eventually develop in patients with a diagnosis of pure autonomic failure (PAF), tending to be lower in PAF patients who phenoconverted to PD/DLB and higher in those that phenoconverted to probable MSA [59].

Overall, these ancillary tests may help confirm a probable or possible MSA, but the clinical history and the neurological exam remain the key elements in formulating the diagnosis. In this context, distinguishing $\mathrm{PD}$ with $\mathrm{OH}$ from MSA-P can be very difficult clinically. Nonetheless, multiple autopsy studies have demonstrated that the lower brainstem, olfactory bulb, and autonomic nervous system are the areas affected earliest in the course of PD (Braak stage 1) [60, 61]. Earlier development of autonomic abnormalities is associated with postural instability and gait difficulty PD motor (PIGD) subtype, poorer levodopa treatment response and represents an independent determinant of more rapid disease progression and shorter survival in patients with PD [62, 63]. Furthermore, dysautonomia, especially baseline orthostatic blood pressure drop, is increasingly reported as a risk factor for development of dementia and is conceivable that $\mathrm{OH}$ may underlie fluctuations in PD dementia [64]. 
Likewise, autonomic symptoms seem to be particularly prevalent in DLB and their prevalence is most likely underestimated because patients have cognitive impairment that could impede their ability to report the presence of autonomic disturbances. Severity and distribution of autonomic failure in DLB fall intermediately between PD and MSA, even though the most common autonomic symptom appears to be orthostatic intolerance [65] and $\mathrm{OH}$ was the only symptom associated with shorter survival in 30 patients with DLB and Parkinson's disease dementia (PDD) [66]. Autonomic features generally become evident later in the course of DLB, but they can be also common in the early stages and a presentation with prominent or isolated dysautonomia combined with parkinsonism in the absence of dementia has been reported, underscoring the broad clinical spectrum within which DLB may present $[12,67,68]$. Postuma et al. [69] demonstrated that patients who develop PD and DLB from idiopathic RBD have clear abnormalities of autonomic function years before the diagnosis of disease. In a case series of 90 patients with DLB, more than half displayed dysautonomic symptoms (particularly $\mathrm{OH}$ ) prior to the onset of cognitive impairment [70]. In agreement with such findings, functional imaging studies show that early on in DLB, as well in PD, amine uptake in postganglionic sympathetic neurons to the heart is already impaired [71].

\section{Cognitive dysfunction across $\alpha$-synucleinopathies}

The time of onset of dementia and less severe cognitive deficits in PD is highly variable but the majority of patients will develop dementia if they survive for more than 10 years after diagnosis with a cumulative incidence approaching $80 \%$ in some community studies [72]. However, newly diagnosed idiopathic PD patients can have measurable cognitive decline at an early stage of disease [13, 73], highlighting cognitive impairment as a key feature from the time of diagnosis of PD and that the ascending pattern of $\alpha$-syn deposits probably does not apply to all the clinical phenotypes of PD [74]. Several previous studies of patients with untreated PD have shown frequencies of PD-MCI between 14.8 and $42.5 \%$ with early PD patients who exhibit impaired performance on a wide range of standardized neuropsychological tests [75-77]. Furthermore, early cognitive deficits are associated with worse motor and non-motor features and have high prognostic value for predicting dementia in patients with PD [78]. In particular, a worse performance in neuropsychological tasks that involve more posterior cortical function is considered a more robust predictor for global cognitive decline in patients with PD [79]. In light of these evidences, the MDS task force, commissioned to consider a redefinition of PD, suggested that the presence of dementia should no longer be exclusionary for the diagnosis of PD and to abolish the '1-year rule' separating PD and DLB [80]. Notwithstanding, this has been a source of controversy [81], and it is still not clear whether DLB and PDD are distinct disorders or the same disease at different stages. Indeed, both entities are closely related to notable overlap in their clinical presentation, pathological features, biochemistry, and genetic risk factors [82]. Of note, most studies have not found reliable differences in neuropsychological function between PDD and DLB, with prominent executive dysfunction and visual-spatial abnormalities and variable impairment in memory capacities [83, 84]. Thus, the temporal sequence of dementia versus motor signs, which is the current distinguishing feature between the two disorders, may not be considered the optimal method for a diagnostic distinction in clinical practice, and many as half of all patients with DLB are also misdiagnosed with another type of dementia [85].

Moreover, the identification of a DLB prodrome may result in a reduced confidence in differentiating DLB from PD [17]. It is acknowledged that DLB can be preceded by amnestic or nonamnestic cognitive impairment, with nonamnestic MCI patients at a substantially higher risk of developing DLB than clinically probable Alzheimer's disease (AD) [86]. Therefore, prodromal phase of DLB potentially identifies the non-demented individuals with DLB pathophysiological processes, whose cognitive deficits do not interfere with their capacity for independence in everyday activities. Research criteria for the diagnosis of MCI-DLB have now been published, and they wait for validation for use in clinical practice [87]. Additionally, other core and suggestive features of DLB, such as fluctuating cognition, RBD and primary autonomic dysfunction, may emerge before patients develop a fully manifest DLB suggesting that prodromal DLB may exhibit different patterns of symptom onset and presentation [87-89]. Indeed, prodromal signs and symptoms of parkinsonism may be also present in prodromal DLB and are generally described as mild, precluding a diagnosis of PD but resulting indistinguishable from the subtle motor dysfunction of prodromal PD [90-92]. Moreover, the study of cognition in PD has shifted to increasingly early or initial cognitive decline and poor cognitive functioning has been associated with an increased risk of parkinsonism in participants of the Rotterdam Study, even after restricting the analysis to patients with incident parkinsonism without dementia, suggesting that cognitive dysfunction can be considered a sign of prodromal PD [93]. Thus, the distinction between DLB and PD with cognitive impairment is unlikely to be useful or practicable at this stage and a general classification of 'prodromal LB disease' seems to be more appropriate [94]. This potential overlap has been demonstrated also in patients with pure autonomic failure (PAF), an $\alpha$-synucleinopathy of the peripheral autonomic nervous system. Indeed, PAF poses a similar prognostic dilemma, because after a period of time some patients may variably 
convert to a central nervous system synucleinopathy (PD, DLB or MSA) [59].

Further, MSA cases present often with atypical features deviating from the classic well-delineated clinical phenotypes of MSA-P and MSA-C so that the clinical spectrum of MSA has expanded over recent years [41]. For example, a $30-70 \%$ of patients with MSA may show an initial good therapeutic response to levodopa [95], some patients may present with asymmetric parkinsonism [96] and others may develop motor complications, including motor fluctuations and levodopa-induced dyskinesias [97]. Moreover, a slow progression of parkinsonism resembling PD have occasionally been reported [98], especially in the MSA-P type and in early-onset MSA patients [99]. Further complicating matters, classically nonsupporting features of MSA that could be helpful in differentiating MSA from PD/ DLB, may develop in patients with MSA: visual hallucinations have been reported to occur in 5-9\% of patients with MSA [100] whereas fluctuating cognition has never been systemically studied to date in MSA [101]. Importantly, neuropsychiatric symptoms such as depression/apathy and anxiety commonly occur in MSA, ranging from 46 to $80 \%$ and 37 to $54 \%$, respectively, and are reported to be more severe and prevalent in MSA-P patients [102]. Similarly, although dementia was considered a nonsupportive criterion in the diagnosis of MSA according to the second consensus statement [22], increasing evidence suggests that cognitive impairments are an integral part of the disease [101] and dementia can occur with estimates reported in the range of 22-37\% in autopsy-confirmed MSA patients [103], whereas some cognitive impairment can be present in up to $75 \%$ of MSA patients [104]. Several studies reported that patients with MSA exhibit more severe cognitive impairment, compared with that of severity- and age-matched patients with PD $[105,106]$. Intriguingly, in a comparative study of cognitive impairment in DLB, MSA, and PD, the MSA group consistently performed in an intermediate level between the $\mathrm{PD}$ and DLB group [2]. The interval from MSA diagnosis to clinically significant cognitive symptoms is estimated to be 7 years on average [107]. However, the presence of cognitive decline among MSA patients who undergo neuropsychological assessment has been also reported at disease onset and, in some patients, the cognitive impairment has preceded motor impairment [108]. Studies on cognitive function in MSA not only disclosed a broad spectrum of deficits in cognition and behavior describing frequently a profile that can be similar to that seen in PD and DLB, with predominant deficits in processing speed, verbal memory, and executive function [109, 110], but visuospatial and constructional dysfunction have also been reported [111]. Similar to PD, MMSE does not seem sufficient to assess cognition in these patients [112] and MoCA seems to be more sensitive to detect the mild cognitive decline in MSA [113]. The cognitive dysfunction in patients with MSA-P showed a tendency to be more severe and widespread than that of patients with MSA-C, albeit relatively few detailed neuropsychological evaluations have been made in the MSA-C subgroup and few studies have addressed the possible differences between patients with predominant cerebellar or parkinsonian presentation [114, 115]. Attentive-executive functions are most likely declined in MSA which suggests a predominant frontal-subcortical pattern of cognitive dysfunction. Imaging studies and neuropathological findings support the idea that the cognitive decline in MSA originates predominantly from the frontal lobe involvement but recent data suggest that MSA and PD cognitive manifestations are associated with distinct underling mechanisms, indicating only a marginal contribution of cortical pathology but more impact of focal fronto-striatal degeneration $[109,116]$. Parallel lines of evidence also indicate that the cerebellum is a potential region of interest for understanding cognitive deficits in both MSA-P and MSA-C subtypes [117]. However, the heterogeneous nature of this pathology has been confirmed in autopsy-confirmed MSA cases that presented a clinical disease type of frontotemporal dementia [118]. Intriguingly, published results show that patients with MSA and dementia had significantly reduced ${ }^{[} 122^{]}$I-MIBG cardiac uptake compared with the patients without dementia hampering further the diagnosis and differential diagnosis of MSA [108]. Cardiovascular dysautonomia emerged as an independent predictor of cognitive impairment in MSA [119].

Overall, there is increasing evidence of a striking relationship between dysautonomia and cognitive problems in neurodegenerative diseases, notably in $\alpha$-synucleinopathies [120, 121], and several pathological mechanisms, not mutually exclusive, have been proposed to explain their association [122]. OH is a common symptom in demented patients, including patients with $\mathrm{AD}$ and frontotemporal dementia [123] and is associated with an increase in long-term risk of dementia [124]. Despite the prevalence of dysautonomia in DLB, no association with cognitive impairment has been reported. In contrast, in early PD, cognitive impairment has been clearly associated with neurocirculatory abnormalities, especially $\mathrm{OH}$ [125]. However, the literature addressing the relationship between cardiovascular autonomic failure and cognitive symptoms in PD has provided contradictory results [126-129] and it remains unclear whether such link is causative or associative. $\mathrm{OH}$ and cognitive impairment could be simply markers of a shared pathologic substrate in $\alpha$-synucleinopathies and disease progression alone may account for this observed association, even though this is unlikely in early stages of disease. Of note, the two entities could be related because the same degenerating brain regions, such as the anterior cingulate cortex, control both cognitive and cardiovascular autonomic processes [130]. Additionally, there is considerable support that transient 
decrements in cognition following postural change in PD patients are independently related to a failure of cerebral autoregulation during orthostatic stress [131, 132]. Finally, the association between $\mathrm{OH}$ and cognitive decline might reflect a common widespread peripheral and central noradrenergic loss [133].

\section{Conclusion}

Whatever the explanation, clinicians should consider incorporating both autonomic and functional cognitive assessments in all persons with $\alpha$-synucleinopathies regardless of subjective concerns brought forth by the patient. Early diagnosis of PD, DLB and MSA can still be challenging based exclusively on clinical findings because patients can show isolated or predominant cognitive disturbances and autonomic symptoms. This group may be misdiagnosed and overlooked if only predetermined criteria based on parkinsonism and dementia are used. In $\alpha$-synucleinopathies, there are several possible clinical starting points and trajectories with a common final pathological and clinical syndrome, likewise a similar clinical pattern at disease onset may evolve over time into either PD, DLB, or MSA. Several observations challenge the weighting of early dysautonomia and cognitive dysfunction in DLB, PD, and MSA, highlighting critical issues associated with current diagnostic criteria. The combination of multimodal markers, including functional and molecular imaging, as well as cerebrospinal fluid and plasma biomarkers, will be helpful for both establishing early diagnostic criteria and for clinically definitive categorization of $\alpha$-synucleinopathies in our continuing efforts to identify individuals at the earliest stages of the disease who would benefit from early symptomatic treatment and for inclusion in future trials.

Author contributions GP and EDP drafted the manuscript and revised it. $\mathrm{UB}$ and $\mathrm{RC}$ revised the manuscript.

Funding Not applicable.

\section{Compliance with ethical standards}

Conflicts of interest The authors declare that there are no conflicts of interest relevant to this work.

Ethical approval This study has been approved by the appropriate ethics committee and has, therefore, been performed in accordance with the ethical standards laid down in the 1964 Declaration of Helsinki and its later amendments.

Consent to participate All persons gave their informed consent prior to inclusion in the study.

Consent for publication All authors have approved the version to be published.

\section{References}

1. Spillantini MG, Goedert M (2000) The alpha-synucleinopathies: Parkinson's disease, dementia with Lewy bodies, and multiple system atrophy. Ann N Y Acad Sci 920:16-27

2. Kao AW, Racine CA, Quitania LC, Kramer JH, Christine CW, Miller BL (2009) Cognitive and neuropsychiatric profile of the synucleinopathies: Parkinson disease, dementia with Lewy bodies, and multiple system atrophy. Alzheimer Dis Assoc Disord 23(4):365-370

3. Hughes AJ, Daniel SE, Ben-Shlomo Y, Lees AJ (2002) The accuracy of diagnosis of parkinsonian syndromes in a specialist movement disorder service. Brain 125(4):861-870

4. Mendoza-Velásquez JJ, Flores-Vázquez JF, Barrón-Velázquez E, Sosa-Ortiz AL, Illigens BW, Siepmann T (2019) Autonomic dysfunction in $\alpha$-synucleinopathies. Front Neurol 10:363

5. Colosimo C, Morgante L, Antonini A et al (2010) Non-motor symptoms in atypical and secondary parkinsonism: the PRIAMO study. J Neurol 257(1):5-14

6. Ha AD, Brown CH, York MK, Jankovic J (2011) The prevalence of symptomatic orthostatic hypotension in patients with Parkinson's disease and atypical parkinsonism. Parkinsonism Relat Disord 17(8):625-628

7. Idiaquez J, Roman GC (2011) Autonomic dysfunction in neurodegenerative dementias. J Neurol Sci 305(1-2):22-27

8. Williams-Gray CH, Mason SL, Evans JR, Foltynie T, Brayne C, Robbins TW, Barker RA (2013) The CamPaIGN study of Parkinson's disease: 10-year outlook in an incident population-based cohort. J Neurol Neurosurg Psychiatry 84(11):1258-1264

9. McKeith IG, Boeve BF, Dickson DW et al (2017) Diagnosis and management of dementia with Lewy bodies: fourth consensus report of the DLB Consortium. Neurology 89(1):88-100

10. Stankovic I, Quinn N, Vignatelli L et al (2019) A critique of the second consensus criteria for multiple system atrophy. Mov Disord 34(7):975-984

11. Bonuccelli U, Lucetti C, Del Dotto P, Ceravolo R, Gambaccini G, Bernardini S, Rossi G, Piaggesi A (2003) Orthostatic hypotension in de novo Parkinson's disease. Arch Neurol 60:1400-1404

12. Kaufmann H, Nahm K, Purohit D, Wolfe D (2004) Autonomic failure as the initial presentation of Parkinson disease and dementia with Lewy bodies. Neurology 63(6):1093-1095

13. Kandiah N, Narasimhalu K, Lau PN, Seah SH, Au WL, Tan LC (2009) Cognitive decline in early Parkinson's disease. Mov Disord 24(4):605-608

14. Fiorenzato E, Antonini A, Wenning G, Biundo R (2017) Cognitive impairment in multiple system atrophy. Mov Disord 32(9):1338-1339

15. Postuma RB, Aarsland D, Barone P, Burn DJ, Hawkes CH, Oertel W, Ziemssen T (2012) Identifying prodromal Parkinson's disease: pre-motor disorders in Parkinson's disease. Mov Disord 27(5):617-626

16. Jecmenica-Lukic M, Poewe W, Tolosa E, Wenning GK (2012) Premotor signs and symptoms of multiple system atrophy. Lancet Neurol 11(4):361-368

17. Donaghy PC, O'Brien JT, Thomas AJ (2015) Prodromal dementia with Lewy bodies. Psychol Med 45(2):259-268

18. Postuma RB, Berg D, Stern M et al (2015) MDS clinical diagnostic criteria for Parkinson's disease. Mov Disord 30(12):1591-1601

19. Gibb WR, Lees AJ (1988) The relevance of the Lewy body to the pathogenesis of idiopathic Parkinson's disease. J Neurol Neurosurg Psychiatry 51:745-752

20. Calne DB, Snow BJ, Lee C (1992) Criteria for diagnosing Parkinson's disease. Ann Neurol 32:S125-S127 
21. Gelb DJ, Oliver E, Gilman S (1999) Diagnostic criteria for Parkinson disease. Arch Neurol 56(1):33-39

22. Gilman S, Wenning GK, Low PA et al (2008) Second consensus statement on the diagnosis of multiple system atrophy. Neurology 71(9):670-676

23. Allan LM, Ballard CG, Allen J, Murray A, Davidson AW, McKeith IG, Kenny RA (2007) Autonomic dysfunction in dementia. J Neurol Neurosurg Psychiatry 78(7):671-677

24. Rajput AH, Rozdilsky B, Rajput A (1991) Accuracy of clinical diagnosis in parkinsonism - a prospective study. Can J Neurol Sci 18:275-278

25. Jankovic J, Rajput AH, McDermott MP, Perl DP (2000) The evolution of diagnosis in early Parkinson disease. Parkinson Study Group Arch Neurol 57:369-372

26. Adler CH, Beach TG, Hentz JG et al (2014) Low clinical diagnostic accuracy of early vs advanced Parkinson disease: clinicopathologic study. Neurology 83:406-412

27. Beach TG, Adler CH (2018) Importance of low diagnostic accuracy for early Parkinson's disease. Mov Disord 33(10):1551-1554

28. Postuma RB, Poewe W, Litvan I et al (2018) Validation of the MDS clinical diagnostic criteria for Parkinson's disease. Mov Disord 33(10):1601-1608

29. Rizzo G, Copetti M, Arcuti S, Martino D, Fontana A, Logroscino G (2016) Accuracy of clinical diagnosis of Parkinson disease: a systematic review and meta-analysis. Neurology 86(6):566-576

30. Kalia LV, Lang AE (2015) Parkinson's disease. Lancet 386(9996):896-912

31. Marras C, Lang A (2013) Parkinson's disease subtypes: lost in translation? J Neurol Neurosurg Psychiatry 84(4):409-415

32. Zis P, Martinez-Martin P, Sauerbier A, Rizos A, Sharma JC, Worth PF, Sophia R, Silverdale M, Chaudhuri KR (2015) Nonmotor symptoms burden in treated and untreated early Parkinson's disease patients: argument for non-motor subtypes. Eur J Neurol 22:1145-1150

33. Fereshtehnejad SM, Romenets SR, Anang JB, Latreille V, Gagnon JF, Postuma RB (2015) New clinical subtypes of Parkinson disease and their longitudinal progression: a prospective cohort comparison with other phenotypes. JAMA Neurol 72:863-867

34. Fereshtehnejad SM, Zeighami Y, Dagher A, Postuma RB (2017) Clinical criteria for subtyping Parkinson's disease: biomarkers and longitudinal progression. Brain 140(7):1959-1976

35. Pilotto A, Romagnolo A, Tuazon JA et al (2019) Orthostatic hypotension and REM sleep behaviour disorder: impact on clinical outcomes in $\alpha$-synucleinopathies. J Neurol Neurosurg Psychiatry 90(11): 1257-1263

36. Koga S, Aoki N, Uitti RJ, van Gerpen JA, Cheshire WP, Josephs KA, Wszolek ZK, Langston JW, Dickson DW (2015) When DLB, PD, and PSP masquerade as MSA: an autopsy study of 134 patients. Neurology 85(5):404-412

37. Miki Y, Foti SC, Asi YT, Tsushima E, Quinn N, Ling H, Holton JL (2019) Improving diagnostic accuracy of multiple system atrophy: a clinicopathological study. Brain 142(9):2813-2827

38. Rizzo G, Arcuti S, Copetti M, Alessandria M, Savica R, Fontana A, Liguori R, Logroscino G (2018) Accuracy of clinical diagnosis of dementia with Lewy bodies: a systematic review and meta-analysis. J Neurol Neurosurg Psychiatry 89(4):358-366

39. Fanciulli A, Goebel G, Lazzeri G et al (2019) Early distinction of Parkinson-variant multiple system atrophy from Parkinson's disease. Mov Disord 34(3):440-441

40. Kim HJ, Stamelou M, Jeon B (2016) Multiple system atrophymimicking conditions: Diagnostic challenges. Parkinsonism Relat Disord 22(Suppl 1):S12-S15

41. Fanciulli A, Wenning GK (2015) Multiple-system atrophy. N Engl J Med 372(3):249-263
42. Wenning GK, Ben-Shlomo Y, Hughes A, Daniel SE, Lees A, Quinn NP (2000) What clinical features are most useful to distinguish definite multiple system atrophy from Parkinson's disease? J Neurol Neurosurg Psychiatry 68(4):434-440

43. Riley DE, Chelimsky TC (2003) Autonomic nervous system testing may not distinguish multiple system atrophy from Parkinson's disease. J Neurol Neurosurg Psychiatry 74(1):56-60

44. Kimpinski K, Iodice V, Burton DD et al (2012) The role of autonomic testing in the differentiation of Parkinson's disease from multiple system atrophy. J Neurol Sci 317(1-2):92-96

45. Coon EA, Cutsforth-Gregory JK, Benarroch EE (2018) Neuropathology of autonomic dysfunction in synucleinopathies. Mov Disord 33(3):349-358

46. Merola A, Espay AJ, Zibetti M, Romagnolo A, Rosso M, Maule S, Lopiano L (2017) Pure autonomic failure versus prodromal dysautonomia in Parkinson's disease: Insights from the bedside. Mov Disord Clin Pract 4(1):141-144

47. Nagayama H, Ueda M, Yamazaki M, Nishiyama Y, Hamamoto M, Katayama Y (2010) Abnormal cardiac [(123)I]-meta-iodobenzylguanidine uptake in multiple system atrophy. Mov Disord 25(11):1744-1747

48. Ikeda T, Ikenoshita S, Sakamoto F, Shiraishi S, Nakahara K, Masuda T, Yamashita S (2019) Is 123I-MIBG scintigraphy beneficial or excessive for the diagnosis of Parkinson's disease in the early phase? Neurodegener Dis 19(2):88-95

49. Lippa CF, Duda JE, Grossman M et al (2007) DLB and PDD boundary issues: diagnosis, treatment, molecular pathology, and biomarkers. Neurology 68:812-819

50. Goldstein DS (2006) Orthostatic hypotension as an early finding in Parkinson's disease. Clin Auton Res 16(1):46-54

51. Hiorth YH, Pedersen KF, Dalen I, Tysnes OB, Alves G (2019) Orthostatic hypotension in Parkinson disease: a 7-year prospective population-based study. Neurology 93(16):e1526-e1534

52. Saito F, Tsuchiya K, Kotera M (1992) An autopsied case of Parkinson's disease manifesting Shy-Drager syndrome. Rinsho Shinkeigaku 32(11):1238-1244

53. Benarroch EE, Schmeichel AM, Parisi JE (2000) Involvement of the ventrolateral medulla in parkinsonism with autonomic failure. Neurology 54:963-968

54. Magalhaes M, Wenning GK, Daniel SE, Quinn NP (1995) Autonomic dysfunction in pathologically confirmed multiple system atrophy and idiopathic Parkinson's disease - a retrospective comparison. Acta Neurol Scand 91:98-102

55. Kim HJ, Jeon B, Fung VSC (2016) Role of magnetic resonance imaging in the diagnosis of multiple system atrophy. Mov Disord Clin Pract 4(1):12-20

56. Fanciulli A, Stankovic I, Krismer F, Seppi K, Levin J, Wenning GK (2019) Multiple system atrophy. Int Rev Neurobiol 149:137-192

57. Xu Z, Arbizu J, Pavese N (2018) PET molecular imaging in atypical parkinsonism. Int Rev Neurobiol 142:3-36

58. Alonso-Canovas A, Tembl Ferrairó JI, Martínez-Torres I et al (2019) Transcranial sonography in atypical parkinsonism: how reliable is it in real clinical practice? A multicentre comprehensive study. Parkinsonism Relat Disord 68:40-45

59. Kaufmann H, Norcliffe-Kaufmann L, Palma JA et al (2017) Natural history of pure autonomic failure: a United States prospective cohort. Ann Neurol 81(2):287-297

60. Braak H, Del Tredici K, Rüb U, de Vos RA, Jansen Steur EN, Braak E (2003) Staging of brain pathology related to sporadic Parkinson's disease. Neurobiol Aging 24(2):197-211

61. Braak H, de Vos RA, Bohl J, Del Tredici K (2006) Gastric alphasynuclein immunoreactive inclusions in Meissner's and Auerbach's plexuses in cases staged for Parkinson's disease-related brain pathology. Neurosci Lett 396(1):67-72 
62. Goldstein DS, Holmes C, Sharabi Y, Wu T (2015) Survival in synucleinopathies: a prospective cohort study. Neurology 85(18):1554-1561

63. De Pablo-Fernandez E, Tur C, Revesz T, Lees AJ, Holton JL, Warner TT (2017) Association of autonomic dysfunction with disease progression and survival in Parkinson disease. JAMA Neurol 74(8):970-976

64. Anang JBM, Gagnon JF, Bertrand JA, Romenets SR, Latreille V, Panisset M, Montplaisir J, Postuma RB (2014) Predictors of dementia in Parkinson disease: a prospective cohort study. Neurology 83:1253-1260

65. Thaisetthawatkul P, Boeve BF, Benarroch EE, Sandroni P, Ferman TJ, Petersen R, Low PA (2004) Autonomic dysfunction in dementia with Lewy bodies. Neurology 62:1804-1809

66. Stubendorff K, Aarsland D, Minthon L, Londos E (2012) The impact of autonomic dysfunction on survival in patients with dementia with Lewy bodies and Parkinson's disease with dementia. PLoS ONE 7(10):e45451

67. Pakiam AS, Bergeron C, Lang AE (1999) Diffuse Lewy body disease presenting as multiple system atrophy. Can J Neurol Sci 26:127-131

68. Yamanaka Y, Asahina M, Hiraga A, Sakakibara R, Oka H, Hattori T (2007) Over 10 years of isolated autonomic failure preceding dementia and Parkinsonism in 2 patients with Lewy body disease. Mov Disord 22(4):595-597

69. Postuma RB, Gagnon JF, Pelletier A, Montplaisir J (2013) Prodromal autonomic symptoms and signs in Parkinson's disease and dementia with Lewy bodies. Mov Disord 28:597-604

70. Fujishiro H, Iseki E, Nakamura S, Kasanuki K, Chiba Y, Ota K, Murayama N, Sato K (2013) Dementia with Lewy bodies: early diagnostic challenges. Psychogeriatrics 13:128-138

71. Manabe Y, Inui Y, Toyama H, Kosaka K (2017) 123I-metaiodobenzylguanidine myocardial scintigraphy with early images alone is useful for the differential diagnosis of dementia with Lewy bodies. Psychiatry Res Neuroimaging 261:75-79

72. Hely MA, Reid WG, Adena MA, Halliday GM, Morris JG (2008) The Sydney multicenter study of Parkinson's disease: the inevitability of dementia at 20 years. Mov Disord 23:837-844

73. Foltynie T, Brayne CE, Robbins TW, Barker RA (2004) The cognitive ability of an incident cohort of Parkinson's patients in the UK. The CamPaIGN Study Brain 127(3):550-560

74. Savica R, Boeve BF, Mielke MM (2018) When Do $\alpha$-synucleinopathies start? An epidemiological timeline: a review. JAMA Neurol 75(4):503-509

75. Aarsland D, Bronnick K, Larsen JP, Tysnes OB, Alves G, Norwegian ParkWest Study Group (2009) Cognitive impairment in incident, untreated Parkinson disease: the Norwegian ParkWest study. Neurology 72:1121-1126

76. Poletti M, Frosini D, Pagni C, Baldacci F, Nicoletti V, Tognoni G, Lucetti C, Del Dotto P, Ceravolo R, Bonuccelli U (2012) Mild cognitive impairment and cognitive-motor relationships in newly diagnosed drug-naive patients with Parkinson's disease. J Neurol Neurosurg Psychiatry 83:601-606

77. Yarnall AJ, Breen DP, Duncan GW et al (2014) Characterizing mild cognitive impairment in incident Parkinson disease: the ICICLE-PD study. Neurology 82:308-316

78. Schrag A, Siddiqui UF, Anastasiou Z, Weintraub D, Schott JM (2017) Clinical variables and biomarkers in prediction of cognitive impairment in patients with newly diagnosed Parkinson's disease: a cohort study. Lancet Neurol 16(1):66-75

79. Williams-Gray CH, Foltynie T, Brayne CE, Robbins TW, Barker RA (2007) Evolution of cognitive dysfunction in an incident Parkinson's disease cohort. Brain 130(7):1787-1798

80. Berg D, Postuma RB, Bloem B et al (2014) Time to redefine PD? Introductory statement of the MDS task force on the definition of Parkinson's disease. Mov Disord 29(4):454-462
81. Boeve BF, Dickson DW, Duda JE et al (2016) Arguing against the proposed definition changes of PD. Mov Disord 31(11):1619-1622

82. Jellinger KA (2018) Dementia with Lewy bodies and Parkinson's disease-dementia: current concepts and controversies. J Neural Transm (Vienna) 125(4):615-650

83. Gomperts SN (2016) Lewy body dementias: dementia with lewy bodies and Parkinson disease dementia. Cont. (Minneap Minn) 22:435-463

84. Aldridge GM, Birnschein A, Denburg NL, Narayanan NS (2018) Parkinson's disease dementia and dementia with lewy bodies have similar neuropsychological profiles. Front Neurol 9:123

85. Jellinger KA, Korczyn AD (2018) Are dementia with Lewy bodies and Parkinson's disease dementia the same disease? BMC Med 16(1):34

86. Ferman TJ, Smith GE, Kantarci K et al (2013) Nonamnestic mild cognitive impairment progresses to dementia with Lewy bodies. Neurology 81:2032-2038

87. McKeith IG, Ferman TJ, Thomas AJ et al (2020) Research criteria for the diagnosis of prodromal dementia with Lewy bodies. Neurology 94(17):743-755

88. Jicha GA, Schmitt FA, Abner E, Nelson PT, Cooper GE, Smith CD, Markesbery WR (2010) Prodromal clinical manifestations of neuropathologically confirmed Lewy body disease. Neurobiol Aging 31:1805-1813

89. McKeith I, Taylor JP, Thomas A, Donaghy P, Kane J (2016) Revisiting DLB diagnosis: a consideration of prodromal DLB and of the diagnostic overlap with alzheimer disease. J Geriatr Psychiatry Neurol 29(5):249-253

90. Berg D, Postuma RB, Adler CH et al (2015) MDS research criteria for prodromal Parkinson's disease. Mov Disord 30(12):1600-1611

91. Simonet C, Schrag A, Lees AJ, Noyce AJ (2019) The motor prodromes of Parkinson's disease: from bedside observation to large-scale application. J Neurol. https://doi.org/10.1007/s0041 5-019-09642-0

92. van de Beek M, van Steenoven I, van der Zande JJ, Barkhof F, Teunissen CE, van der Flier WM, Lemstra AW (2020) Prodromal dementia with lewy bodies: clinical characterization and predictors of progression. Mov Disord 35(5):859-867

93. Darweesh SKL, Wolters FJ, Postuma RB, Stricker BH, Hofman A, Koudstaal PJ, Ikram MK, Ikram MA (2017) Association between poor cognitive functioning and risk of incident parkinsonism: the rotterdam study. JAMA Neurol 74(12):1431-1438

94. Donaghy PC, McKeith IG (2014) The clinical characteristics of dementia with Lewy bodies and a consideration of prodromal diagnosis. Alzheimers Res Ther 6(4):46

95. Wenning GK, Geser F, Krismer F et al (2013) The natural history of multiple system atrophy: a prospective European cohort study. Lancet Neurol 12(3):264-274

96. Batla A, Stamelou M, Mensikova K, Kaiserova M, Tuckova L, Kanovsky P, Quinn N, Bhatia KP (2013) Markedly asymmetric presentation in multiple system atrophy. Parkinsonism Relat Disord 19(10):901-905

97. Jost WH, Lingor P, Tönges L, Schwarz J, Buhmann C, Kassubek J, Schrag A (2019) Dyskinesia in multiple system atrophy and progressive supranuclear palsy. J Neural Transm (Vienna) 126(7):925-932

98. Petrovic IN, Ling H, Asi Y, Ahmed Z, Kukkle PL, Hazrati L-N, Lang AE, Revesz T, Holton JL, Lees AL (2012) Multiple system atrophy-parkinsonism with slow progression and prolonged survival: a diagnostic catch. Mov Disord 27(9):1186-1190

99. Batla A, De Pablo-Fernandez E, Erro R et al (2018) Young-onset multiple system atrophy: clinical and pathological features. Mov Disord 33:1099-1107 
100. Watanabe H, Riku Y, Hara K, Kawabata K, Nakamura T, Ito M, Hirayama M, Yoshida M, Katsuno M, Sobue G (2018) Clinical and imaging features of multiple system atrophy: challenges for an early and clinically definitive diagnosis. J Mov Disord 11(3):107-120

101. Stankovic I, Krismer F, Jesic A et al (2014) Cognitive impairment in multiple system atrophy: a position statement by the neuropsychology task force of the MDS multiple system atrophy (MODIMSA) study group. Mov Disord 29(7):857-867

102. Zhang L, Cao B, Ou R, Wei Q-Q, Zhao B, Yang J, Wu Y, Shang $\mathrm{H}$ (2017) Non-motor symptoms and the quality of life in multiple system atrophy with different subtypes. Parkinsonism Relat Disord 35:63-68

103. Cykowski MD, Coon EA, Powell SZ, Jenkins SM, Benarroch EE, Low PA, Schmeichel AM, Parisi JE (2015) Expanding the spectrum of neuronal pathology in multiple system atrophy. Brain 138:2293-2309

104. Auzou N, Dujardin K, Biundo R, Foubert-Samier A, Barth C, Duval F, Tison F, Defebvre L, Antonini A, Meissner WG (2015) Diagnosing dementia in multiple system atrophy by applying Movement Disorder Society diagnostic criteria for Parkinson's disease dementia. Parkinsonism Relat Disord 21(10):1273-1277

105. Pillon B, Gouider-Khouja N, Vidailhet DB, Malapani C, Dubois B, Agid Y, (1995) Neuropsychological pattern of striatonigral degeneration: comparison with Parkinson's disease and progressive supranuclear palsy. J Neurol Neurosurg Psychiatry 58:174-179

106. Soliveri P, Monza D, Paridi D, Carella F, Genitrini S, Testa D, Girotti F (2000) Neuropsychological follow up in patients with Parkinson's disease, striatonigral degeneration-type multisystem atrophy, and progressive supranuclear palsy. J Neurol Neurosurg Psychiatry 69:313-318

107. O'Sullivan SS, Massey LA, Williams DR, Silveira-Moriyama L, Kempster PA, Holton JL, Revesz T, Lees AJ (2008) Clinical outcomes of progressive supranuclear palsy and multiple system atrophy. Brain 131:1362-1372

108. Kitayama M, Wada-Isoe K, Irizawa Y, Nakashima K (2009) Assessment of dementia in patients with multiple system atrophy. Eur J Neurol 16:589-594

109. Koga S, Parks A, Uitti RJ, van Gerpen JA, Cheshire WP, Wszolek ZK, Dickson DW (2017) Profile of cognitive impairment and underlying pathology in multiple system atrophy. Mov Disord 32(3):405-413

110. Eschlböck S, Delazer M, Krismer F et al (2020) Cognition in multiple system atrophy: a single-center cohort study. Ann Clin Transl Neurol 7(2):219-228

111. Kim HJ, Jeon BS, Kim YE, Kim JY, Kim YK, Sohn CH, Yun JY, Jeon S, Lee JM, Lee JY (2013) Clinical and imaging characteristics of dementia in multiple system atrophy. Parkinsonism Relat Disord 19:617-621

112. Siri C, Duerr S, Canesi M et al (2013) A cross-sectional multicenter study of cognitive and behavioural features in multiple system atrophy patients of the parkinsonian and cerebellar type. J Neural Transm (Vienna) 120(4):613-618

113. Fiorenzato E, Weis L, Falup-Pecurariu C, Diaconu S, Siri C, Reali E, Pezzoli G, Bisiacchi P, Antonini A, Biundo R (2016) Montreal cognitive assessment (MOCA) and mini-mental state examination (MMSE) performance in progressive supranuclear palsy and multiple system atrophy. J Neural Transm (Vienna) 123:1435-1442

114. Kawai Y, Suenaga M, Takeda A, Ito M, Watanabe H, Tanaka F et al (2008) Cognitive impairments in multiple system atrophy: MSA-C vs MSA-P. Neurology 70(2):1390-1396

115. Chang CC, Chang YY, Chang WN, Lee YC, Wang YL, Lui CC, Huang CW, Liu WL (2009) Cognitive deficits in multiple system atrophy correlate with frontal atrophy and disease duration. Eur J Neurol 16(10):1144-1150

116. Fiorenzato E, Weis L, Seppi K et al (2017) Brain structural profile of multiple system atrophy patients with cognitive impairment. J Neural Transm (Vienna) 124(3):293-302

117. Barcelos LB, Saad F, Giacominelli C, Saba RA, de Carvalho Aguiar PM, Silva SMA, Borges V, Bertolucci PHF, Ferraz HB (2018) Neuropsychological and clinical heterogeneity of cognitive impairment in patients with multiple system atrophy. Clin Neurol Neurosurg 164:121-126

118. Aoki N, Boyer PJ, Lund C et al (2015) Atypical multiple system atrophy is a new subtype of frontotemporal lobar degeneration: frontotemporal lobar degeneration associated with $\alpha$-synuclein. Acta Neuropathol 130:93-105

119. Brown RG, Lacomblez L, Landwehrmeyer BG et al (2010) Cognitive impairment in patients with multiple system atrophy and progressive supranuclear palsy. Brain 133:2382-2393

120. Udow SJ, Robertson AD, MacIntosh BJ, Espay AJ, Rowe JB, Lang AE, Masellis M (2016) 'Under pressure': is there a link between orthostatic hypotension and cognitive impairment in $\alpha$-synucleinopathies? J Neurol Neurosurg Psychiatry 87(12):1311-1321

121. Merola A, Romagnolo A, Dwivedi AK et al (2020) Benign versus malignant Parkinson disease: the unexpected silver lining of motor complications. J Neurol. https://doi.org/10.1007/s0041 5-020-09954-6

122. Sambati L, Calandra-Buonaura G, Poda R, Guaraldi P, Cortelli P (2014) Orthostatic hypotension and cognitive impairment: a dangerous association? Neurol Sci 35(6):951-957

123. Sonnesyn H, Nilsen DW, Rongve A, Nore S, Ballard C, Tysnes OB, Aarsland D (2009) High prevalence of orthostatic hypotension in mild dementia. Dement Geriatr Cogn Disord 28:307-313

124. Wolters FJ, Mattace-Raso FU, Koudstaal PJ, Hofman A, Ikram MA, Heart Brain Connection Collaborative Research Group (2016) Orthostatic Hypotension and the Long-Term Risk of Dementia: A Population-Based Study. PLoS Med 13(10):e1002143

125. Kim JS, Oh YS, Lee KS, Kim YI, Yang DW, Goldstein DS (2012) Association of cognitive dysfunction with neurocirculatory abnormalities in early Parkinson disease. Neurology 79(13):1323-1331

126. Allcock LM, Kenny RA, Mosimann UP, Tordoff S, Wesnes KA, Hildreth AJ, Burn DJ (2006) Orthostatic hypotension in Parkinson's disease: association with cognitive decline? Int J Geriatr Psychiatry 21:778-783

127. Allcock LM, Kenny RA, Burn DJ (2006) Clinical phenotype of subjects with Parkinson's disease and orthostatic hypotension: autonomic symptom and demographic comparison. Mov Disord 21:1851-1855

128. Idiaquez J, Benarroch EE, Rosales H, Milla P, Rios L (2007) Autonomic and cognitive dysfunction in Parkinson's disease. Clin Auton Res 17:93-98

129. Peralta C, Stampfer-Kountchev M, Karner E, Kollensperger M, Geser F, Wolf E, Seppi K, Benke T, Poewe W, Wenning GK (2007) Orthostatic hypotension and attention in Parkinson's disease with and without dementia. J Neural Transm 114:585-588

130. Matsui H, Udaka F, Miyoshi T, Hara N, Tamura A, Oda M, Kubori T, Nishinaka K, Kameyama M (2005) Three-dimensional stereotactic surface projection study of orthostatic hypotension and brain perfusion image in Parkinson's disease. Acta Neurol Scand 112(1):36-41

131. Pilleri M, Facchini S, Gasparoli E, Biundo R, Bernardi L, Marchetti M, Formento P, Antonini A (2013) Cognitive and MRI correlates of orthostatic hypotension in Parkinson's disease. J Neurol 260:253-259 
132. Centi J, Freeman R, Gibbons CH, Neargarder S, Canova AO, Cronin-Golomb A (2017) Effects of orthostatic hypotension on cognition in Parkinson disease. Neurology 88(1):17-24
133. McDonald C, Newton JL, Burn DJ (2016) Orthostatic hypotension and cognitive impairment in Parkinson's disease: Causation or association? Mov Disord 31(7):937-946 